Rev. Elet. em Gestão, Educação e Tecnologia Ambiental (e-ISSN: 2236-1170)

\title{
USINA DE COMPOSTAGEM: UMA OPÇÃO ECONÔMICA E SUSTENTÁVEL
}

\author{
Jaqueline Carla Guse ${ }^{1}$, Aline Zulian ${ }^{2}$, Viviane Schons de Ávila ${ }^{3}$, \\ Andrea Cristina Dörr ${ }^{4}$, Marivane Vestena Rossato ${ }^{5}$ \\ ${ }^{1}$ Universidade Federal de Santa Maria - UFSM: drjaquelinecarla@yahoo.com.br \\ ${ }^{2}$ Universidade Federal de Santa Maria - UFSM:alinezulian@hotmail.com \\ ${ }^{3}$ Universidade Federal de Santa Maria - UFSM: vivideavila@gmail.com \\ ${ }^{4}$ Universidade Federal de Santa Maria - UFSM: andreadoerr@yahoo.com.br \\ ${ }^{5}$ Universidade Federal de Santa Maria - UFSM:marivavest@gmail.com
}

\section{RESUMO}

A busca acelerada por aumento de produtividade e o uso desenfreado de recursos naturais aliados à emissão de resíduos poluentes vem motivando a preocupação com o meio ambiente em muitos setores do agronegócio. Através de uma pesquisa realizada junto a Usina de Compostagem da Cooperativa Ecocitrus, da cidade de Montenegro, na região do Vale do Caí, Rio Grande do Sul, objetivou-se analisar os procedimentos básicos realizados na transformação de resíduos industriais em novo produto, o composto (ou adubo) orgânico, trazendo um novo ciclo àqueles produtos que seriam descartados. Constatou-se que, além desta usina representar um local para as empresas descartarem parte de seus resíduos sem agredir o meio ambiente, ela também beneficia os sócios produtores que compõem a cooperativa Ecocitrus. Estes, por sua vez, recebem gratuitamente o composto orgânico em suas propriedades, substituindo o insumo agroquímico e tendo uma produção de citros orgânica.

Palavras-chave: usina de compostagem, composto orgânico, meio ambiente.

\section{ABSTRACT}

The accelerated search for increased productivity and rampant use of natural resources combined with the emission of pollutants has motivated the concern with the environment in many sectors of agribusiness. Through a survey of the Composting Plant Ecocitrus Cooperative, the city of Montenegro, in the Vale do Cai, Rio Grande do Sul, aimed to analyze the basic procedures performed in the processing of industrial wastes in new product, the organic compound (or fertilizer), bringing a new cycle for those products that would be discarded. It was found that, besides this plant representing a place for companies discard some of their waste without harming the environment, it also benefits the partners that make up the producers of Ecocitrus Cooperative. These, in turn, receive a free compost on their properties, replacing the agrochemical input and having an organic citrus production.

Keywords: composting plant, compost, environment. 
Rev. Elet. em Gestão, Educação e Tecnologia Ambiental (e-ISSN: 2236-1170)

\section{INTRODUÇÃO}

No século XIX, pesquisadores difundiram a ideia de que quanto maior a utilização de produtos químicos for adicionada a terra, maior será a quantidade de alimentos produzidos (EHLERS, 1996). Na agricultura moderna ainda há essa ligação com o passado, em que busca-se primordialmente a proteção das plantações contra pragas, ficando em segundo plano a preocupação com a qualidade dos alimentos, meio ambiente e saúde humana. Entretanto, em 1960 o modelo de agricultura moderna apresentou sinais de exaustão, fatores como a diminuição da fertilidade do solo, erosões, contaminação das águas pelos resíduos de agrotóxicos, foram determinantes para o surgimento da utilização de uma agricultura ecológica e orgânica (EHLERS, 1996).

Com isso, chega-se ao dilema entre lucratividade e sustentabilidade. Para Freitas (2002) a agricultura orgânica pode tornar-se tão lucrativa quanto o sistema químico convencional, inclusive com custos baixos, isso se deve a expansão do mercado consumidor, que está demandando a sustentabilidade através da aquisição de produtos orgânicos. Para este mercado em expansão, uma das formas mais encontradas no cultivo de orgânicos é a agricultura familiar, devido a características como: área de plantio de pequeno porte, culturas diversificadas e auto-sustentáveis e, principalmente, pela mão-de-obra disponível (SMOLINSKI; GUERREIRO; RAIHER, 2011).

Argumentos comprovam a viabilidade da agricultura orgânica para pequenos produtores, como o fato de atenderem um segmento restrito de consumidores que estão dispostos a pagar um preço maior por esses produtos e, ainda, a possibilidade de inserção desses pequenos agricultores em redes nacionais ou transnacionais de comercialização de produtos orgânicos. Outra vantagem é a diversificação da produção que garante a estabilidade da renda durante o ano todo, e a diminuição da dependência de insumos externos devido a menor área plantada e a facilidade de manejo com insumos oriundos da própria propriedade (CAMPANHOLA; VALARINI, 2001).

De acordo com Campanhola e Valarini (2001), a demanda por produtos orgânicos tende a aumentar, devido a fatores como a preocupação dos consumidores com sua saúde e de sua família, preferindo o consumo de alimentos que não contenham resíduos de agrotóxicos, e também devido à preocupação ambiental e social por parte de consumidores que visam preservar o meio ambiente, abrindo espaço ao mercado de alimentos orgânicos. Além disso, o diferencial no preço de mercado dos produtos orgânicos em relação aos produtos convencionais tenderá a desaparecer à medida que a quantidade ofertada de produtos orgânicos aumente e atenda a quantidade demandada desses produtos (CAMPANHOLA; VALARINI, 2001).

No Brasil, a agricultura orgânica é responsável pela produção de soja, açúcar mascavo, hortaliças, frutas, cereais e leguminosas (SMOLINSKI; GUERREIRO; RAIHER, 2011). Com o mercado de orgânicos em expansão, utilizar os conceitos de sustentabilidade e preocupações socioambientais para cultivar alimentos será uma das maneiras para diminuir os danos ao meio ambiente e melhorar a qualidade de vida de todos envolvidos no processo de produção e oferecer alimentos de qualidade ao consumidor final.

Segundo Rondinelli e Berry (2000), durante a última década, o conceito de desenvolvimento sustentável ampliou-se para incluir simultaneamente o crescimento econômico, a proteção ambiental e a equidade social em planejamento de negócios e tomada de decisões. Além disso, a sustentabilidade tornou-se um imperativo estratégico para as empresas e evoluiu para uma força de mercado fundamental que afeta a viabilidade financeira a longo prazo (ORLITZKY; SCHMIDT; RYNES, 2003). 
Um problema de ordem social, econômica e ambiental, segundo Valente et al. (2009), é o aumento da produção envolvendo produtos da agricultura e pecuária que tem gerado uma quantidade elevada de resíduos sólidos e líquidos (subprodutos da atividade agropecuária e agroindustrial). Desse modo, faz-se necessário adotar medidas para melhor utilização desses resíduos não apenas para a redução de despejo destes no meio ambiente, mas também para elevar a qualidade do solo e reduzir custos do produtor rural.

Nesse sentido, a compostagem aparece como uma alternativa de melhor utilização de resíduos. Segundo Souza e Rezende (2006), a compostagem é a utilização de resíduos orgânicos grosseiros em materiais orgânicos possíveis de serem utilizados na agricultura. Esta prática transforma a matéria orgânica em húmus, gás carbônico, calor e água, através da ação de microorganismos.

Além do uso do adubo orgânico representar um dos itens para diferenciação da produção de modo a torná-la orgânica, ele é importante para aumento da produtividade. Segundo Diniz Filho et al. (2007), a compostagem mostra-se como uma prática muito importante para a melhoria e garantia qualidade do solo, aumentando a produtividade das culturas desde a germinação, desenvolvimento da planta, até a produção vegetal em si.

Com a utilização das terras para fins de agricultura, os estoques de matéria orgânica no solo tendem a diminuir, pois a dinâmica dessa matéria orgânica no solo é influenciada pelas práticas de preparo do solo e pela escolha das espécies cultivadas. Nesse sentido, a adição de matéria orgânica ao solo é fundamental para a sua qualidade, pois gera uma liberação gradativa de nutrientes que estarão disponíveis às culturas (LEITE et al., 2003). Segundo os mesmos autores, o uso de fertilizantes químicos associados a adubos orgânicos já têm sido recomendados como manejo alternativo na agricultura. Porém, segundo Villas Bôas et al. (2004), a recomendação de doses de adubo varia conforme o tipo de composto orgânico aplicado, com o solo, com a cultura e com as condições ambientais.

Existe na legislação brasileira, no Regulamento da Lei $n \cong 6.894$, de 16 de dezembro de 1980, um conceito próprio para o fertilizante orgânico composto: produto obtido por processo físico, químico, físico-químico ou bioquímico, natural ou controlado, a partir de matéria-prima de origem industrial, urbana ou rural, animal ou vegetal, isoladas ou misturadas, podendo ser enriquecido de nutrientes minerais, princípio ativo ou agente capaz de melhorar suas características físicas, químicas ou biológicas (BRASIL, 1980).

A produção da matéria orgânica pode ser feita com os resíduos disponíveis na propriedade rural ou em outros departamentos. De acordo com Nunes (2009), no meio agrícola existem muitos resíduos de origem vegetal (folhas, galhos, caules, inflorescências, palhas, sabugos e raízes de plantas alimentícias ou não, cascas de árvores, casca de frutas, que apresentam algum dano causado por insetos ou doenças, bagaços, cama de animais, restos de capins da alimentação animal, restos vegetais resultantes de capinas, colheitas e podas de plantas, algas, plantas aquáticas, etc) e de origem animal (estercos, ossos, casca de ovos, penas, vísceras, cascas de mariscos), que são vistos como lixo, mas que na verdade são excelente fonte de matéria-prima para produção do adubo orgânico. Esses resíduos possuem muitos nutrientes, mas não devem ser usados na forma in natura. Devem passar pelo processo de compostagem aeróbica que transforma-os em adubo orgânico de qualidade (NUNES, 2009). Segundo a definição de Nunes (2009), a compostagem é uma técnica idealizada para obter, no mais curto espaço de tempo, a estabilização ou humificação da matéria orgânica que na natureza se dá em tempo indeterminado. É um processo controlado de decomposição microbiana de uma massa heterogênea de resíduos no estado sólido e úmido. 
A Cooperativa Ecocitrus, de Montenegro, Rio Grande do Sul, Brasil, foca em frutas cítricas e produtos derivados orgânicos. Para viabilizar esse modo de produção, a cooperativa construiu uma Usina de Compostagem para atender a demanda dos sócios pelo insumo orgânico, que é aplicado como fertilizante nas propriedades. Nesse contexto, realizou-se uma pesquisa junto a esta usina, com o objetivo de analisar os procedimentos básicos realizados por ela na transformação de resíduos agroindustriais em um composto (ou adubo) orgânico, representando uma opção sustentável e, além disso, uma opção econômica, através da comercialização do composto.

\section{METODOLOGIA}

\section{Fonte dos dados}

Utilizou-se, para o desenvolvimento deste estudo, tanto a técnica de pesquisa de documentação indireta, via pesquisa bibliográfica em estudos científicos, quanto a documentação direta, constituída da pesquisa de campo na Usina de Compostagem da Cooperativa Ecocitrus (Cooperativa dos Citricultores Ecológicos do Vale do Caí), localizada no município de Montenegro, na região do Vale do Caí, Rio Grande do Sul, Brasil. Desse modo, essa pesquisa de campo é de caráter exploratório-descritivo, envolvendo análises empíricas qualitativas. Foram utilizadas duas técnicas para coleta dos dados primários: a observação e a entrevista com o responsável pela usina e sócio da cooperativa.

Esta pesquisa é caracterizada como estudo de caso. De modo geral, o estudo de caso é aplicável quando se desejam obter generalizações analíticas e não estatísticas, que possam contribuir para certo referencial teórico (LAZZARINI, 1997). O estudo de caso enquadra-se no grupo de métodos denominados qualitativos, que dá maior ênfase na compreensão dos fatos do que propriamente na sua mensuração. Dessa forma, contrasta-se com os métodos quantitativos, que se preocupam mais em mensurar fenômenos e são aplicados a amostras mais extensas (LAZZARINI, 1997).

\section{Área de estudo e análise dos dados}

A citricultura desempenha importante papel na região do Vale do Caí. Conforme a Secretaria Municipal de Agricultura e Meio Ambiente de Montenegro-RS (PREFEITURA MUNICIPAL DE MONTENEGRO, 2011), aproximadamente 4.000 famílias tem a citricultura como a principal fonte de renda.

A Cooperativa Ecocitrus trabalha apenas com produtos orgânicos, sendo que o método de produção orgânico é uma condição necessária para tornar-se sócio. Além de vender a fruta in natura (principalmente tangerina e laranja), a cooperativa faz o suco cítrico e o óleo essencial de tangerina, todos vendidos com o selo de produto orgânico. A Ecocitrus foi construída como uma visão diferente da agricultura convencional e tinha, desde o início, a ideia de agrupar produtores que cultivassem frutas sem a utilização de agroquímicos. Os ideais buscavam manter a família no campo com maior qualidade de vida, diminuição da poluição dos arroios e rios e a redução dos custos dos insumos (agroquímicos eram muito caros). 
Rev. Elet. em Gestão, Educação e Tecnologia Ambiental (e-ISSN: 2236-1170)

A cooperativa é composta por cerca de 110 associados, sendo que sete são produtores e trabalhadores, 42 são sócios trabalhadores, 10 são empregados e 61 são agricultores (ECOCITRUS, 2010). Além da sede principal, a entidade possui uma agroindústria e uma usina de compostagem. Essa usina de compostagem recicla 45 mil toneladas de resíduos industriais por ano (ECOCITRUS, 2010) e destina o composto orgânico para a propriedade dos sócios, substituindo o adubo químico.

O estudo foi realizado em março de 2011, utilizando-se da técnica da entrevista de um sócio responsável pela usina de compostagem da Ecocitrus. A coleta de dados primários consistiu na aplicação de um formulário com perguntas abertas. Após isso, as informações foram computadas e analisadas qualitativamente.

\section{RESULTADOS E DISCUSSÃO}

A seguir, encontra-se a análise dos procedimentos básicos realizados pela usina de compostagem na transformação de resíduos agroindustriais em composto (ou adubo) orgânico e de que forma isso beneficia economicamente os produtores orgânicos.

\section{A Usina de Compostagem}

Segundo a Ecocitrus (2010), em 1995 a cooperativa criou uma base de beneficiamento de adubos orgânicos chamada de Usina de Compostagem de Resíduos Agroindustriais. Isso foi possibilitado através de um investimento de $\mathrm{R} \$ 78.000,00$ oriundos da Deutsche Gesellschaft für Technische Zusammenarbeit (GTZ) - entidade de fomento da Alemanha. Com este recurso, adquiriu-se o maquinário e alugou-se o terreno onde se encontra a sede da usina. Desse modo, em parceria com 35 agroindústrias da região, os resíduos orgânicos destas empresas são destinados para a usina, que os transforma em adubo orgânico.

O foco da usina é a reutilização de resíduos já resultantes de um processo produtivo. Ou seja, gera-se um novo ciclo de vida a estes resíduos e, ainda, a substituem-se todos os produtos químicos utilizados no processo produtivo, procurando uma atividade econômica e sustentável. Ao todo, segundo a Ecocitrus (2010), a cooperativa recicla 45 mil toneladas de resíduos industriais e produz 15 mil toneladas de composto (sólido) e 15 mil toneladas de biofertilizante líquido por ano.

A partir do início de suas atividades a usina passou a ser uma central para produtos orgânicos. Os produtos que chegam até a usina são somente aqueles que têm foco na agricultura orgânica. Sendo assim, a usina está constantemente em busca de melhora, pois com mais tecnologia e com a etiqueta de registro no Ministério da Agricultura, Pecuária e Abastecimento (MAPA), consegue-se comercializar os insumos para outros mercados da região.

Vale destacar que, em 2008, a Ecocitrus fez um grande investimento na remodelação da estrutura da Usina de Compostagem, construindo novas valas e pavilhões. A usina, que ocupa 12 hectares, na localidade de Passo da Serra (Montenegro-RS), foi modernizada com a introdução de novas tecnologias como: a aceleração do processo de compostagem, que melhorou a qualidade do adubo orgânico (ECOCITRUS, 2010). Segundo a mesma fonte, a usina detinha uma licença de operação para 3,4 mil metros cúbicos mensais. E, na renovação desta licença, a Fundação Estadual 
Rev. Elet. em Gestão, Educação e Tecnologia Ambiental (e-ISSN: 2236-1170)

de Proteção Ambiental (FEPAM) autorizou o processamento de 12 mil metros cúbicos de resíduos "Classe II" por mês.

\section{Processo de transformação de resíduos}

A biomassa, resultado de restos de serrarias e madeireiras, é a matéria-prima básica do composto produzido pela usina. Os resíduos a serem transformados são obtidos em um raio de $200 \mathrm{~km}$ de distância da usina. As empresas sem o ISO 14001 podem destinar os resíduos para os aterros ou para a compostagem. Já uma empresa que possui o selo ISO 14001 deve obedecer às regras da legislação para destinar os resíduos de forma mais sustentável possível, tendo em vista a reutilização do mesmo resíduo em um novo processo produtivo. Dessa forma, a usina de compostagem é uma opção viável, uma vez que é sustentável e econômica para a destinação dos resíduos industriais.

A empresa vendedora dos resíduos pode realizar o transporte ou a cooperativa busca na empresa. Existem contratos regulamentando as prestações de serviços e também contratos de concessão de resíduos com as empresas.

Do processo de conversão de resíduos em composto orgânico resulta em uma redução da biomassa de resíduos de entrada em $60 \%$, ou seja, no final do processo tem-se $40 \%$ de composto orgânico do total de resíduos transformados. Como o produto não é perecível e tem uma digestão aeróbica, quanto maior o tempo que fica na usina, menor é o volume de composto resultante, porém adquire-se uma melhor qualidade.

Todo o processo de transformação dos resíduos em adubo composto é realizado em quatro meses, sendo que com uma estrutura melhor poder-se-ia diminuir este prazo para 35 dias. O adubo biodinâmico, o qual é um composto mais amadurecido, em que há um crescimento maior de microorganismos, leva mais 6 a 12 meses após todo o processo de transformação para ficar pronto, e ainda recebe preparos biodinâmicos.

A usina tem licença para a produção de 12.000 toneladas por mês. No momento da entrevista, março de 2011, a usina possuía biomassa em torno de 10.000 toneladas, e destinava para o mercado cerca de 3.500 toneladas em forma de três produtos: o composto orgânico (cerca de 2.000 toneladas), biofertilizante líquido (cerca de 1.000 toneladas) e a cinza (cerca de 500 toneladas). Ressalta-se que o adubo biodinâmico estava em fase de experimentação no momento da entrevista.

\section{Comercialização: benefício econômico}

Os produtos são destinados para os sócios da cooperativa e também para terceiros. Os sócios não têm nenhum custo com os compostos e com a logística de transporte e aplicação destes em suas propriedades. As propriedades recebem somente a quantidade que a equipe técnica da cooperativa julga ser suficiente para a área a ser aplicada. Além disso, esta equipe faz constantes análises de solo e das folhas nas propriedades dos sócios. Fica evidente que além do benefício ambiental, o composto traz vantagens para os sócios da cooperativa Ecocitrus, que não tem custos com fertilizantes.

E, além disso, a cooperativa comercializa o composto para terceiros, também representando uma fonte de renda extra para esta sociedade. A equipe técnica da cooperativa também faz o licenciamento e a análise da área onde vai ser aplicado o produto. A cinza é doada a 
Rev. Elet. em Gestão, Educação e Tecnologia Ambiental (e-ISSN: 2236-1170)

qualquer pessoa desde que seja feita análise técnica do local a ser aplicado o produto, tendo como custo somente o transporte.

Os preços dos adubos compostos são diferenciados para produtores ecológicos e para os produtores em processo de transição da agricultura convencional para a agricultura orgânica. Assim, o preço do adubo composto para os produtores que não são orgânicos (não sócios) é de R\$ 40,00 por metro cúbico e para os produtores sócios em transição (que estão inserindo-se no sistema de produção orgânica) é $50 \%$ mais barato. Com esta estratégia, a cooperativa visa difundir a prática orgânica e ecológica.

Além de vender o composto orgânico produzido, a usina presta serviços de transformação de resíduos em composto orgânico às empresas industriais, ou seja, a usina apenas transforma o resíduo e a empresa é responsável pelo destino final. O preço médio da prestação de serviços é de $\mathrm{R} \$ 60,00 /$ ton.

O pagamento dos serviços e produtos é feito à vista e a prazo. A usina tem uma inadimplência de $R \$ 150.000,00$ em média, sendo que destes, $R \$ 40.000,00$ já são consideradas perdas. A prestação de serviços tem menos inadimplência que a venda de produtos. A política de contas a receber é o não fornecimento de produtos e serviços aos clientes inadimplentes.

\section{Estrutura administrativa}

Para a coordenação dos trabalhos na usina de compostagem, conta-se com um geólogo, uma bióloga doutora em contaminação do solo, e ainda outro biólogo que se ocupa da bioquímica, além de outros profissionais na área administrativa e outros serviços. A maioria (90\%) da mão-de-obra utilizada é dos sócios da cooperativa Ecocitrus.

A usina de compostagem tem um faturamento mensal médio de $\mathrm{R} \$ 300.000,00$ (rentabilidade é de $50 \%$ deste montante) onde o custo com pessoal representa $20 \%$. A usina ainda tem um custo com energia de $\mathrm{R} \$ 5.000,00$ por mês, além do aluguel da área da usina e de custos com equipamentos e combustíveis.

A contabilidade da cooperativa é toda formal, sendo realizada com sistemas próprios. São feitas notas fiscais de todas as operações, inclusive das doações. Além disso, são feitos as análises dos balanços e balancetes gerados.

A usina tem um plano de investimentos para melhorar sua infraestrutura para um maior controle do processo e para diminuir o impacto ambiental. Pretende-se, ainda, cobrir as duas lagoas de produção de biofertilizantes para captar o gás metano, que é liberado no processo aeróbico, para geração de energia, evitando a liberação de gases poluentes.

Todos os investimentos são realizados com recursos próprios. A área ocupada pela usina é de 12 hectares, os quais são utilizados há 8 anos e tem um custo de $R \$ 5.000,00$ mensais. Em março de 2011, estava sendo acordado o aluguel de mais um hectare, o qual teria um custo de $\mathrm{R} \$$ $1.250,00$ mensais. Esta área é do mesmo proprietário, o que possui 80 hectares, a qual a cooperativa pretende futuramente adquirir para ampliação da usina.

\section{CONCLUSÕES}

A usina de compostagem é um exemplo de trabalho sustentável, pois transforma os resíduos em novos produtos, trazendo um novo ciclo àquele produto que seria descartado. $A$ usina realiza trabalhos de assistência aos produtores, tanto associados como não associados, 
Rev. Elet. em Gestão, Educação e Tecnologia Ambiental (e-ISSN: 2236-1170)

visando principalmente o incentivo a agricultura orgânica. Para tanto, fornece os adubos orgânicos de forma gratuita a seus associados e pela metade do preço a produtores adeptos à agricultura orgânica. Essa ação traz a disseminação da consciência ecológica aos produtores da região, ajudando cada vez mais a preservação do meio ambiente.

Além disso, a usina de compostagem é uma opção para as empresas descartarem seus resíduos de forma sustentável, sendo eles reutilizados e não jogadas no meio ambiente. A empresa não incorre em gasto com a entrega de seus resíduos à usina. Ainda, um dos benefícios à empresa, além de preservar o meio ambiente, é melhorar a sua imagem corporativa, e consequentemente as relações com os grupos interessados.

A cooperativa ainda preocupa-se em cada vez mais adquirir técnicas avançadas para diminuir os gases poluentes emitidos na transformação dos resíduos em composto orgânico. Isso demonstra a conscientização e a preocupação ambiental despendida pela usina.

Conclui-se que atividades como esta que é realizada pela Usina de Compostagem são importantes para a preservação do meio ambiente. Esta se constitui numa opção viável para descarte de resíduos industriais e um meio pelo qual os produtores orgânicos conseguem produzir os alimentos de forma natural e economicamente viável, via redução nos custos de produção. Além de representar uma vantagem aos produtores com a distribuição do composto, a sociedade cooperativa se beneficia com a comercialização do adubo orgânico para terceiros.

É notória a necessidade de divulgar trabalhos como este para que cada vez mais se consigam investimentos e parcerias para atividades como esta. Além disso, o trabalho realizado pela usina serve de exemplo para a comunidade em geral e para a comunidade empresarial, no sentido de incentivar a consciência ecológica juntamente com o crescimento econômico.

\section{AGRADECIMENTO}

Os autores agradecem a Fundação de Amparo à Pesquisa do Estado do Rio Grande do Sul (FAPERGS) que contribuiu com o financiamento do estudo.

\section{REFERÊNCIAS}

BRASIL. Regulamento da Lei no 6.894, de 16 de dezembro de 1980 . Disponível em: <http://www.agrolink.com.br/fertilizantes/arquivos/decretos/decreto_4954[1].pdf>. Acesso em: 28 mai. 2012.

CAMPANHOLA, C.; VALARINI, P. J. A agricultura orgânica e seu potencial para o pequeno agricultor. Cadernos de Ciência \& Tecnologia, Brasília, v. 18, n. 3, p. 69-101, 2001.

DINIZ FILHO, E. T. et al. A prática da compostagem no manejo sustentável de solos. Revista Verde de Agroecologia e Desenvolvimento Sustentável, v. 2, n. 2, p. 27-36, 2007.

ECOCITRUS. Cooperativa 2010.2 Disponível em: <http://www.ecocitrus.com.br/cooperativa.htm>. Acesso em: 24 fev. 2012. 
Rev. Elet. em Gestão, Educação e Tecnologia Ambiental (e-ISSN: 2236-1170)

EHLERS, E. Agricultura sustentável: origens e perspectivas de um novo paradigma. São Paulo: Livros da Terra, 1996.

FREITAS, J. C. de. Agricultura Sustentável: Uma análise comparativa dos fatores de produção entre Agricultura Orgânica e Agricultura Convencional. 2002. Dissertação (Mestrado em Economia) Departamento de Economia. Universidade de Brasília, Brasília.

LAZZARINI, S. G. Estudos de Caso para Fins de Pesquisa: Aplicabilidade e Limitações do Método. In: FARINA et al. (Coord.). Estudos de Caso em Agribusiness. São Paulo: Pioneira, 1997. p. 9-23.

LEITE, L. F. C. et al. Estoques totais de carbono orgânico e seus compartimentos em Argissolo sob floresta e sob milho cultivado com adubação mineral e orgânica. Revista Brasileira de Ciência do Solo, v. 27, p. 821-832, 2003.

NUNES, M. U. C. Compostagem de Resíduos para Produção de Adubo Orgânico na Pequena Propriedade. Circular Técnica da Embrapa, Aracaju, n. 59, 2009.

ORLITZKY, M.; SCHMIDT, F. L.; RYNES, S. L. Corporate social and financial performance: a metaanalysis. Organisation Studies, v. 24, p. 403-442, 2003.

PREFEITURA MUNICIPAL DE MONTENEGRO. Secretaria Municipal de Agricultura e Meio Ambiente de Montenegro: dados citricultura. Rio Grande do Sul, 2011. Disponível em: $<$ http://www.montenegro.rs.gov.br/home/show_page.asp?user=\&id_CONTEUDO=2098\&codID_C AT=503\&imgCAT=\&id_SERVICO=\&categoria=Munic\%EDpio>. Acesso em: 05 mai. 2011.

RONDINELLI, D. A.; BERRY, M. A. Environmental citizenship in multinational corporations: social responsibility and sustainable development. European Management Journal, v. 18, n. 1, p. 70-84, 2000. Disponível em: <http://www.sciencedirect.com/science/article/pii/S0263237399000705>. Acesso em: 07 jun. 2012. http://dx.doi.org/10.1016/S0263-2373(99)00070-5.

SMOLINSKI, R.; GUERREIRO, E.; RAIHER, A. P. Análise do mercado de produtos orgânicos: estudo de caso de feira em Ponta Grossa, PR. Revista Desenvolvimento e Meio Ambiente, Ponta Grossa, v. 23, p. 167-182, 2011.

SOUZA, J. L. de; REZENDE, P. L. Manual de Horticultura Orgânica. 2a ed. Viçosa: Aprenda Fácil. 2006. $843 \mathrm{p}$.

VALENTE, B. $S$ et al. Fatores que afetam o desenvolvimento da compostagem de resíduos orgânicos. Arch. Zootec., v. 58, p. 59-85, 2009. Disponível em: <http://www.uco.es/organiza/servicios/publica/az/php/img/web/07_18_48_1395REVISIONFatore sValente1.pdf>. Acesso em: 28 mai. 2012.

VILLAS BÔAS, R. L. et al. Efeito de doses e tipos de compostos orgânicos na produção de alface em dois solos sob ambiente protegido. Revista Horticultura Brasileira, Brasília, v. 22, n. 1, p. 28-34, 2004. 